\title{
A New Identification Method Reveals the Resistance of an Extensive-Source Radish Collection to Plasmodiophora brassicae Race 4
}

\author{
Haohui Yang ${ }^{1}$, Yuxiang Yuan ${ }^{2}$, Xiaochun Wei ${ }^{2}$, Xiaohui Zhang ${ }^{1}$, Haiping Wang ${ }^{1}$, Jiangping Song ${ }^{1}$ \\ and Xixiang $\mathrm{Li}^{1}$,*
}

Citation: Yang, H.; Yuan, Y.; Wei, X.; Zhang, X.; Wang, H.; Song, J.; Li, X. A New Identification Method Reveals the Resistance of an Extensive-Source Radish Collection to Plasmodiophora brassicae Race 4. Agronomy 2021, 11, 792. https://doi.org/10.3390/ agronomy 11040792

Academic Editor: Hans Rediers

Received: 18 March 2021

Accepted: 13 April 2021

Published: 17 April 2021

Publisher's Note: MDPI stays neutral with regard to jurisdictional claims in published maps and institutional affiliations.

Copyright: (c) 2021 by the authors. Licensee MDPI, Basel, Switzerland. This article is an open access article distributed under the terms and conditions of the Creative Commons Attribution (CC BY) license (https:/ / creativecommons.org/licenses/by/ $4.0 /)$.
1 Key Laboratory of Biology Genetic Improvement of Horticultural Crops, Institute of Vegetables and Flowers, Chinese Academy of Agricultural Sciences, Ministry of Agriculture, Beijing 100081, China; yanghaohui127@163.com (H.Y.); Zhangxiaohui01@caas.cn (X.Z.); wanghaiping@caas.cn (H.W.); songjiangping@caas.cn (J.S.)

2 Institute of Horticulture, Henan Academy of Agricultural Sciences, Zhengzhou 450002, China; yuxiangyuan@126.com (Y.Y.); jweixiaochun@126.com (X.W.)

* Correspondence: lixixiang@caas.cn; Tel.: +86-10-8210-5947

\begin{abstract}
Raphanus sativus, an important cruciferous vegetable, has been increasingly affected by clubroot disease. Establishing a stable and accurate resistance identification method for screening resistant germplasms is urgently needed in radish. In this study, the influence of inoculum concentration, inoculation methods, and $\mathrm{pH}$ of the substrate on disease occurrence was studied. The result showed that the disease index (DI) was highest at $2 \times 10^{8}$ spores $/ \mathrm{mL}$, the efficiency of two-stage combined inoculation methods was higher than others, and $\mathrm{pH} 6.5$ was favorable for the infection of $P$. brassicae. By using this new method, DIs of 349 radish germplasms varying from 0.00 to 97.04 , presented significantly different levels of resistance. Analysis showed that $85.06 \%$ germplasms from China were susceptible to $P$. brassicae, whilst 28 accessions were resistant and mainly distributed in east, southwest, northwest, and south-central China. Most of the exotic germplasms were resistant. Repeated experiments verified the stability and reliability of the method and the identity of germplasm resistance. In total, 13 immune, 5 highly resistant and 21 resistant radish accessions were identified. This study provides an original clubroot-tolerance evaluation technology and valuable materials for the development of broad-spectrum resistant varieties for sustainable clubroot management in radish and other cruciferous crops.
\end{abstract}

Keywords: radish germplasms; identification technology; clubroot; distribution of clubroot-resistance; sustainable management strategy

\section{Introduction}

Clubroot disease caused by the soil-borne obligate pathogen Plasmodiophora brassicae Woronin is one of the most common and serious diseases in cruciferous crops worldwide. It is widespread in Europe, North America, and Asia, especially in East Asia [1]. In China, approximately one-third of cultivated areas of Brassicaceae vegetables have been infected, leading to a loss of production of nearly $60 \%$ [2]. The production of radish (Raphanus sativus L.), an important vegetable crop, has also been seriously threatened by this disease in many growing areas of China, such as Henan, Sichuan, Hubei, and Yunnan provinces [3-6].

Historically, Plasmodiophora brassicae has been studied in many aspects $[7,8]$ and is classified as an amoeboid protozoan in the infrakingdom Rhizaria [9-12]. The pathogen is a kind of eukaryote and belongs to the Plasmodiophorales [1]. The infection process of host plants comprises a primary phase and a secondary phase $[13,14]$. These two phases occur separately, mainly in root hairs and cortical tissue, while the first phase can also 
occur in epidermal cells [13]. Although the significance of both phases during the course of infection by P. brassicae is not well understood, typical symptoms include the formation of galls that are irregular, nonhomogeneous, or even twisty after the secondary infection [14]. Consequently, these galls, which are also called "clubs", impede the transport of nutrients and water between the aboveground and underground parts of the plant, leading to growth retardation, yellowing, stunting, and a decrease in quality and yield [15,16]. In addition, the resting spores from the root tissues filled with secondary plasmodia after cortical infection (the secondary phase) are ultimately released into the soil and can stay alive for up to 17 years $[17,18]$.

Due to the persistent vitality and the diversification of transmission of resting spores in the soil, it is difficult to completely and effectively manage the disease. Currently, the main strategies used to control clubroot are reducing the incidence and severity of clubroot disease in infested regions and avoiding infestation of clubroot-free areas [19]. In order to protect clubroot-free areas from clubroot, transmission routes are usually cut off by sanitizing mediums such as machinery, nursery substrates, and water [20]. However, some studies have reported difficulties in managing open irrigation systems with resting spores [21]. Concerning reducing the clubroot incidence and severity of infested fields, chemical or agrotechnical measures are the most commonly and widely used. The main chemicals are fungicides or fumigants. Fungicides, such as flusulfamide, alone or together with quintozene and chlorothalonil, have been used to control disease incidence [22]. Fumigants have also been reported to have a clear protective effect against clubroot disease [23]. However, both fungicides and fumigants are a potential threat to the environment. In addition, taking advantage of liming and crop rotation to reduce clubroot represent the main agrotechnical strategies that have been utilized [24], but liming was not consistently effective [25], while crop rotation between cruciferous crops is a time-consuming process [26-28]. Biological control with Tricboderma species is another alternative to manage clubroot based on its environmentally friendly nature, though one study reported the instability of reducing clubroot incidence in some regions [29]. Thus far, direct or indirect utilization of resistant varieties, especially with durable resistance, is considered the most effective approach to manage clubroot disease.

In order to genetically improve resistance in Brassicaceae crops, the resistance of germplasms to P. brassicae has been evaluated in B. rapa [30-37], B. oleracea [32,38-44], B. napus [45-50], B. nigra [42], B. juncea [34,42], B. carinata [34,42], and some other Brassica species. Among B. rapa accessions that were identified early, the majority of Chinese cabbage (B. rapa ssp. pekenensis) cultivars were highly susceptible, while some turnips (B. rapa ssp. rapifera) showed high resistance [7]. Early on, clubroot resistance (CR) was introduced to Chinese cabbage by means of hybridization with turnips [51]. Subsequently, genetic analyses and gene mapping of CR were conducted in $B$. rapa. Thus far, at least $21 \mathrm{CR}$ loci have been identified in $B$. rapa, including $C R a, C R b, C R c, C R k, C r r 1, C r r 2, C r r 3$, Crr4, PbBa3.1, PbBa3.3, QS_B3.1, Rcr1, Rcr2, Rcr4, Rcr8, Rcr9, CRd, qBrCR38-1, qBrCR382, CRs, and PbBrA08 ${ }^{\text {Banglim }}$ [7,8,11,52-63]. Most CR loci originate from European fodder turnip $[7,8,52-56,58,60]$ and other sources including Pak choi, B. rapa canola, and Chinese cabbage [11,57,59-63]. In B. oleracea, resistant materials were identified in many studies, but only a few materials were found to be highly resistant. It was also found that CR might be controlled by quantitative trait loci (QTL) [64], and a few QTL have been proven to be related to CR in B. oleracea [65-73]. Furthermore, a single dominant CR gene from B. oleracea was mapped recently [74]. In B. napus, a few resistant resources have been found in previous studies [75,76]. Single gene and major QTL of B. napus were mapped [39,77-79]. Although extensive work on screening resources resistant to clubroot and some CR gene mapping has been done in Brassica crops, it is difficult to use the resistant materials from those crops directly for radish breeding. Thus far, only a few small-scale studies have dealt with screening resistant sources in radish [80-82].

An accurate identification method is very important for precisely distinguishing plant disease resistance. However, there has been no unified standard system of precise large- 
scale identification of clubroot-resistance in Brassicaceae crops so far. According to relative information, the artificial inoculation of $P$. brassicae in the seedling period is mainly affected by the inoculation method, inoculum concentration, $\mathrm{pH}$ of seedling substrate, etc. This has been reported in B. rapa and B. oleracea [83-91]. Clubroot-soil (mix substrate with inoculum), dipping root (dipping root in inoculum), injecting (injecting inoculum to surrounding seed, bud or seedling), and soaking (soaking seed or bud in inoculum) have comprised the main inoculation methods used in Brassicaceae crops. The Effect of the inoculation method varies in different species, as studies focusing on inoculation methods have shown that the clubroot-soil method is considered to be better than other methods in B. oleracea [84-86], while the dipping root method is better than the others in B. rapa [87-90]. In most cases, inoculation was given only once at the seedling stage, which may result in missed or underdosed inoculation. In addition, the optimal concentration was mainly setup at three magnitudes: $10^{7}, 10^{8}, 10^{9}$ spores $/ \mathrm{mL}$ varying in different species [85,89,92]. The optimal $\mathrm{pH}$ of seedling substrate was mainly between 5-6.5 [86,91-93]. In radish, no research on the effect of different inoculation method, inoculation times, inoculation concentration and $\mathrm{pH}$ of seedling substrate has been conducted.

In the present study, the effects of different inoculum concentrations, inoculation methods, and $\mathrm{pH}$ of the seedling substrate were compared and a stable and reliable screening method was established. Based on the method optimized, 349 accessions of representative radish germplasms conserved in the National Mid-term Genebank of Vegetable Germplasm Resources (NMGVGR) were evaluated for their reactions to P. brassicae race 4 . Understanding the resistance distribution and the acquisition of diverse resistant sources will be helpful for the discovery of new clubroot resistant genes and resistance genetic improvement in radish and other cruciferous crops.

\section{Material and Methods}

\subsection{Plant Materials}

Radish cultivar 791 (known to be susceptible), provided by Henan Academy of Agricultural Sciences (HAAS), was used in the study of the identification method and in the large-scale evaluation as a susceptible control.

A total of 349 accessions of radish germplasms were studied, including 328 indigenous and 21 exotic germplasm accessions. The indigenous radish accessions were provided by the National Mid-term Genebank of Vegetable Germplasm Resources in Beijing (NMGVGR) and were originally collected from 230 counties or cities of 29 provinces or municipalities belonging to six geographic regions (https:/ / en.wikipedia.org/wiki/List_of_regions_of_ China, accessed on 23 October 2020). They were classified into six groups corresponding to their original Chinese geographic regions. Exotic radish accessions were categorized into Group 7. Detailed information on all germplasms in this study is listed in Table S1.

\subsection{Pathogen Preparation}

P. brassicae race 4 [94] was used in this study for its high prevalence in China. The clubbed roots isolated from infected Chinese cabbage root tissues (collected from Nanyang City, Henan Province, China) were first washed with tap water and finally with sterile water, and then air-dried and stored at $-20^{\circ} \mathrm{C}$. The preparation of the resting spore inoculum was based on the method of Luo et al. [95]. The swollen roots were homogenized with a two-fold volume of distilled water using a blender and were then filtered through four layers of cheesecloth. The filtrate was collected and centrifuged twice at $4000 \times g$ for $10 \mathrm{~min}$. The precipitate/spores were washed twice with sterile water. Finally, the spores were resuspended and adjusted to the corresponding concentration using a hemocytometer. P. brassicae race 4 was identified using differential hosts [96].

\subsection{Plant Cultivation and Treatment}

Comparison of different inoculum concentration 
The seeds of "791" was pre-germinated in Petri dishes with 2 layers of moist filter paper at $25^{\circ} \mathrm{C}$ until the length of bud measured $5 \mathrm{~mm}$. Then, thirty germinated seeds of " $791^{\prime \prime}$ for each spore concentration treatment were sown into small pots of $10 \mathrm{~cm}$ diameter with a drenched sterile peat-vermiculite mixture $(1: 1, v / v)$ as the seedling substrate. The inoculum concentration was adjusted to $2 \times 10^{9}, 2 \times 10^{8}, 2 \times 10^{7}, 2 \times 10^{6}$ spores $/ \mathrm{mL}$, respectively, and $5 \mathrm{~mL}$ of resting spore inoculum was injected onto the surface of germinating seeds in each pot. The control materials were injected with the same amount of sterile water.

Comparison of different artificial inoculation methods based on the concentration of $2 \times 10^{8}$ spores $/ \mathrm{mL}$

Injecting bud: Thirty pre-germinating seeds of "791" according to the method mentioned above were sown into the seedling-raising pots. Meanwhile, $5 \mathrm{~mL}$ of resting spore inoculum was injected onto the surface of germinating seeds in each pot. Stirring of inoculum should be done during inoculation to avoid sedimentation. The control materials were injected with $5 \mathrm{~mL}$ sterile water.

Soaking bud: Thirty germinating seeds of "791" were soaked into resting spore inoculum for $45 \mathrm{~min}$ [91]. The control materials were soaked in sterile water for an equal amount of time.

Injuring roots: The seedling was grown according to the procedure used for the injecting method. The difference was that the inoculation was carried out at the two trueleaf stage. The lateral and fibrous roots of thirty seedlings were gashed down from the substrate surface at a distance of $2 \mathrm{~cm}$ away from the stem base of each seedling, followed by a separate injection of $5 \mathrm{~mL}$ inoculum. The control materials were injected in $5 \mathrm{~mL}$ sterile water.

Two-stage combined inoculation: When the length of the bud was $5 \mathrm{~mm}$ after pregermination, thirty germinating seeds of "791" were sown into small pots, and $5 \mathrm{~mL}$ of resting spore inoculum were injected onto the surface of germinating seeds in each pot. When the seedlings grew to the two true-leaf stage, the lateral and fibrous roots were gashed down from the substrate surface at a distance of $2 \mathrm{~cm}$ away from the stem base of each seedling, followed by a separate injection of $5 \mathrm{~mL}$ inoculum. The control materials were injected with $5 \mathrm{~mL}$ of sterile water at the first and second inoculation in the same way.

Clubroot-soil: The sterile peat-vermiculite mixture was drenched with resting spore inoculum. Then, 25-30 g of clubroot-soil was placed into a small hole made in the center of pots [85]. Subsequently, thirty germinating seeds without any subsequent inoculation were also planted.

Comparison of different $\mathrm{pH}$ of substrate based on the concentration of $2 \times 10^{8}$ spores $/ \mathrm{mL}$

Thirty pre-germinated seeds of "791" per $\mathrm{pH}$ were sown into small pots with a drenched sterile peat-vermiculite mixture $(1: 1, v / v)$. The mixture $\mathrm{pH}$ was adjusted to 5.5, $6.0,6.5$, and 7.0, respectively. Meanwhile, $5 \mathrm{~mL}$ of resting spore inoculum was injected onto the surface of germinated seed in each pot. The $\mathrm{pH}$ of the substrate was adjusted by using Hoagland nutrient solution with hydrochloric acid or potassium hydroxide. Next, the seedlings were watered with nutrient solution of corresponding $\mathrm{pH}$.

Resistance evaluation of a large-scale germplasm resources

Based on the identification method established, 349 accessions of radish germplasms were inoculated with $2 \times 10^{8}$ spores $/ \mathrm{mL}$ inoculum by using the two-stage inoculation of combining injecting bud and injury seedling root method, as above.

The germinated seeds or seedlings were kept moist and watered less in the first week after inoculation (to prevent the inoculum from being washing away), but watered more from the second week, ensuring that P. brassicae could infect the root hairs and cortical tissues adequately.

Experiment design

A completely randomized block design was arranged in three biological replicates and 10 seedlings for each replicate (20 seedlings for each replicate of the control cultivar). All pots were placed in the isolation area in an identification chamber at the Institute of 
Vegetables and Flowers of the Chinese Academy of Agricultural Sciences (Beijing, China), and protected by an insect-proof net. The average temperature was $20-25^{\circ} \mathrm{C}$ and the plants were maintained under a $14 \mathrm{hL} / 10 \mathrm{hD}$ photoperiod. In addition, Hoagland nutrient solution was watered according to the growth requirements of seedlings [97]. The seedlings of $\mathrm{pH}$ experiment were watered with nutrient solution of corresponding $\mathrm{pH}$.

Verification of the new method and germplasm resistance

All immune accessions and parts of highly susceptible accessions were arranged in a second assessment trial to verify the stability of their resistance and the reproducibility of the identification trials.

\subsection{Data Collection}

To ensure that the seedlings had been fully infected before investigation, two seedlings of the susceptible control cultivar 791 were pulled out and observed for disease status every week, starting from the third week after the second inoculation. As a result, disease severity was evaluated on the 65 th day after sowing. The improved evaluation criteria of root symptoms in radish crops were established based on the study by Kamei et al. [82] and previous studies as follows: grade 0 , all roots symptom-free; grade 1 , taproots symptomfree, slightly swollen fibrous roots/lateral roots or 1-2 small clubs on fibrous roots/lateral roots; grade 3, slightly swollen taproots and/or multiple small galls on 1/3 1/2 lateral roots; grade 5, medium swollen taproots or a few galls on taproots, or more irregular tumors on 1/2 2/3 lateral roots; grade 7, lager and swollen taproots and/or many mallet/ clubroots on more than 2/3 lateral roots; grade 9, extremely swollen taproots with severe clubbed lateral roots, partial decay of roots. The disease index (DI) based on the disease severity was calculated according to Strelkov et al. [98] using the modified formula:

$$
\mathrm{DI}(\%)=\frac{\sum(\mathrm{s} \times \mathrm{n})}{\mathrm{N} \times \mathrm{S}} \times 100
$$

where $\mathrm{s}$ is the value for each grade, $\mathrm{n}$ is the number of plants at each grade, $\mathrm{N}$ is the total number of tested plants, $S$ means the value for the highest grade. The DI value of each accession was calculated based on the average DI value of three replicates. The resistance of each accession was evaluated according to the following criteria:

Immune (I): DI = 0; Highly Resistant (HR): $0<\mathrm{DI} \leq 5$; Resistant (R): $5<\mathrm{DI} \leq 15$; Moderately Resistant (MR): $15<\mathrm{DI} \leq 30$; Susceptible (S): $30<\mathrm{DI} \leq 60$; Highly Susceptible (HS): DI > 60 .

\subsection{Data Analysis}

Data analysis was conducted using statistical analysis software (SAS version 9.3). A paired t-test was used to test the stability of the DIs of immune/susceptible materials between the first inoculation and the re-inoculation $(p<0.05)$. Analysis of Variance (ANOVA) with Duncan's multiple range test (PROC GLM statistical procedure) was performed to determine whether there was a significant difference among different inoculation conditions $(p<0.05)$.

\section{Results}

3.1. Influence of Different Inoculum Concentrations, Inoculation Methods, and $p H$ of Substrate on Severity of Clubroot Disease in Radish

The influence of different inoculum concentrations on disease severity was studied by setting four levels: $2 \times 10^{9}, 2 \times 10^{8}, 2 \times 10^{7}$, and $2 \times 10^{6}$ spores $/ \mathrm{mL}$. The disease incidence of four levels was $100 \%$, while the disease severity varied significantly among different concentrations. The mean DIs of three biological replicates of $2 \times 10^{9}, 2 \times 10^{8}$, $2 \times 10^{7}$, and $2 \times 10^{6}$ spores $/ \mathrm{mL}$ were $62.84,70.00,64.90$, and 56.36 , and the DI of $2 \times 10^{8}$ spores $/ \mathrm{mL}$ was the highest (Figure 1). ANOVA indicated that the degree of disease severity of $2 \times 10^{8}$ spores $/ \mathrm{mL}$ was significantly different from other concentrations, but there was no statistically significantly difference with $2 \times 10^{9}$ and $2 \times 10^{7}$ spores $/ \mathrm{mL}$ 
$(p<0.05)$. Based on the concentration of $2 \times 10^{8}$ spores $/ \mathrm{mL}$, inoculation methods and $\mathrm{pH}$ of substrate were compared. All plants in these two experiments were infected. According to the DIs of different inoculation methods, the plants ( $\mathrm{DI}=87.30)$ of two-stage combined inoculation were most severely infected and significantly different from the other methods, as determined by ANOVA $(p<0.05)$. There were no statistically significant differences among the soaking bud (DI = 62.59), injuring root (DI $=59.79)$ and clubroot-soil methods $(\mathrm{DI}=57.04)$; the injecting bud effect was the lowest $(\mathrm{DI}=48.64)$. In the $\mathrm{pH}$ experiment, the disease severity of $\mathrm{pH} 6.5(\mathrm{DI}=79.63)$ was the highest and significantly different from other $\mathrm{pH}$ values, as determined by ANOVA $(p<0.05)$. The optimal $\mathrm{pH}$ condition of plants infected by P. brassicae was weakly acidic (5.5-6.5) rather than neutral.

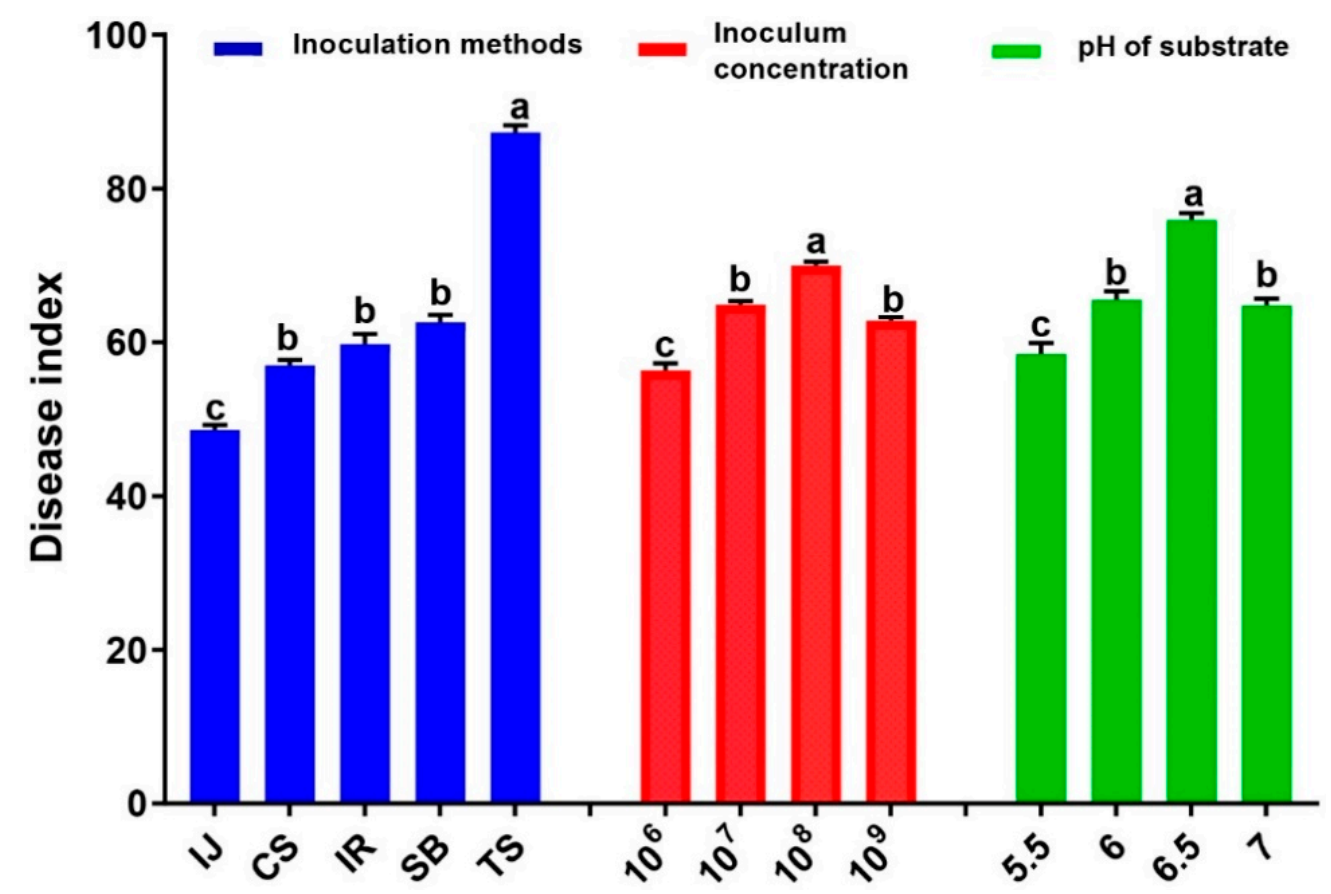

Figure 1. Comparison of different inoculation methods, inoculum concentration and $\mathrm{pH}$ of substrate. IJ, Injecting bud method; CS, Clubroot-soil method; IR, Injuring root method; SB, Soaking bud method; TS, Two stage inoculation method. $10^{6}, 2 \times 10^{6}$ spores $/ \mathrm{mL} ; 10^{7}, 2 \times 10^{7}$ spores $/ \mathrm{mL} ; 10^{8}$, $2 \times 10^{8}$ spores $/ \mathrm{mL} ; 10^{9}, 2 \times 10^{9}$ spores $/ \mathrm{mL}$. Values $5.5,6,6.5$, and 7 refer to different $\mathrm{pH}$ levels. Means of DI followed by different letters indicate statistically significant differences according to Duncan's multiple range test $(p<0.05)$.

\subsection{The Resistance of Radish Germplasms to P. brassicae Race 4}

In this study, 349 radish germplasms were inoculated using the newly established two-stage combined inoculation method based on $2 \times 10^{8}$ spores $/ \mathrm{mL}$. The DIs from 0.00 to 97.04 (Table S1) varied significantly among all radish germplasms. According to the resistance classification standard mentioned above, most radish accessions $(81.66 \%)$ were susceptible to $P$. brassicae, including 81 susceptible materials and 204 highly susceptible materials. Fortunately, 41 accessions (11.75\%) exhibited resistance to clubroot. Among these materials, 21 accessions were resistant, 5 accessions showed high resistance, whilst 15 accessions revealed no disease symptoms and were identified as immune to $P$. brassicae (Table S1). A phenotype comparison of representative immune vs. highly susceptible radish materials is shown in Figure 2. 


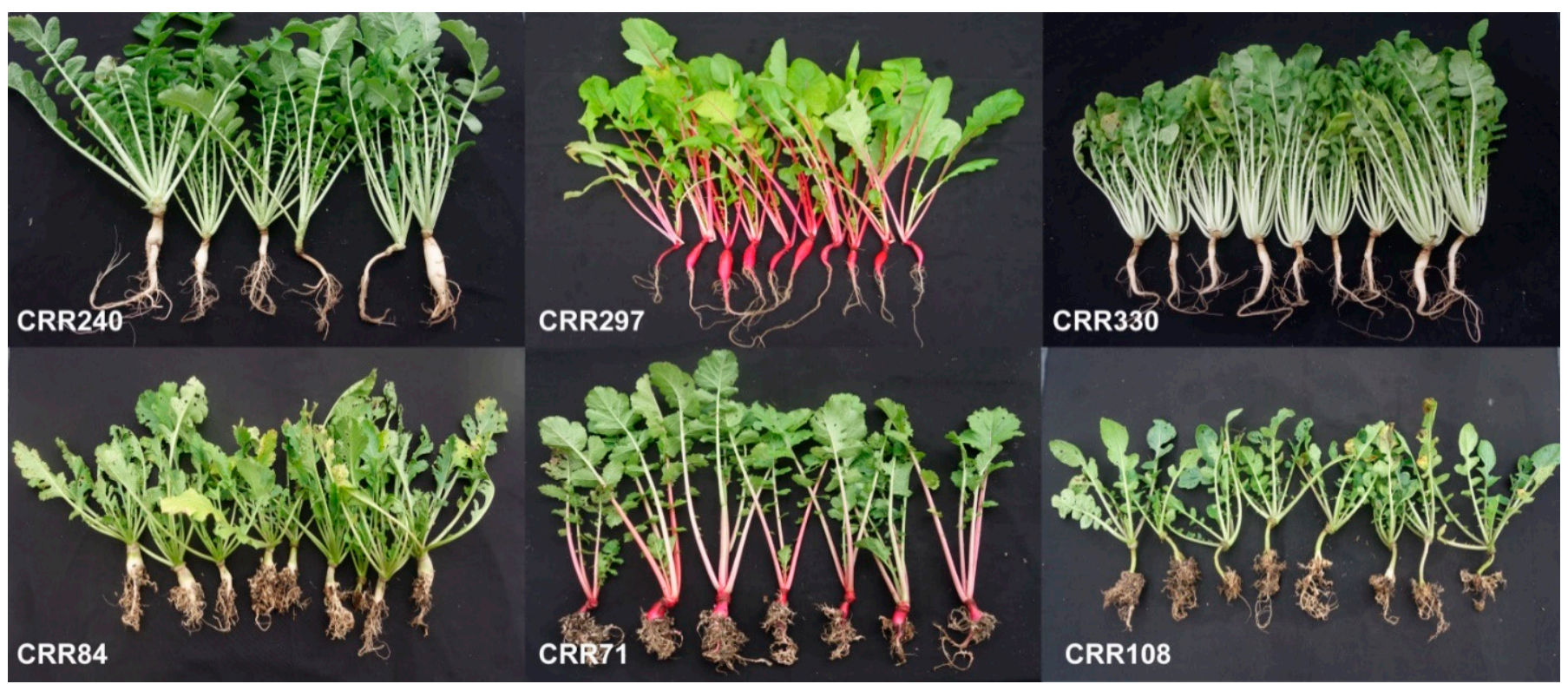

Figure 2. Comparison of the phenotypes of representative radish materials that are either immune or highly susceptible to P. brassicae race 4. CRR240, CRR297, and CRR330 illustrate the resistance of immune germplasms; CRR84, CRR71, and CRR108 show disease symptoms of highly susceptible germplasms.

\subsection{Geographic Distribution of the Radish Resources with Different Resistance to P. brassicae} Race 4

Resistance/susceptibility was also analyzed according to the geographical distribution of 328 accessions of indigenous radish germplasms, which were collected from 230 counties or cities belonging to 29 provinces or municipalities of six geographic regions. A total of 279 susceptible or highly susceptible accessions were distributed in all six geographic regions, especially concentrated in northeast and north China, where no resistant materials were found. The accessions with moderate resistance were mainly located in four geographic regions except northeast and northwest China. However, a total of 28 accessions of resistant materials (including I, HR, and R) were distributed in a dispersed fashion across several provinces of east, southwest, northwest, and south-central China (Figure 3).

Compared with Chinese radish germplasms, most of the exotic radish germplasms were resistant to P. brassicae (Figure 4). A considerable portion of resistant accessions (61.90\% of the total exotic materials) came from Japan, North Korea, South Korea, Russia, Germany, and Spain, especially the immune materials, which accounted for $61.54 \%$ of all immune materials. 

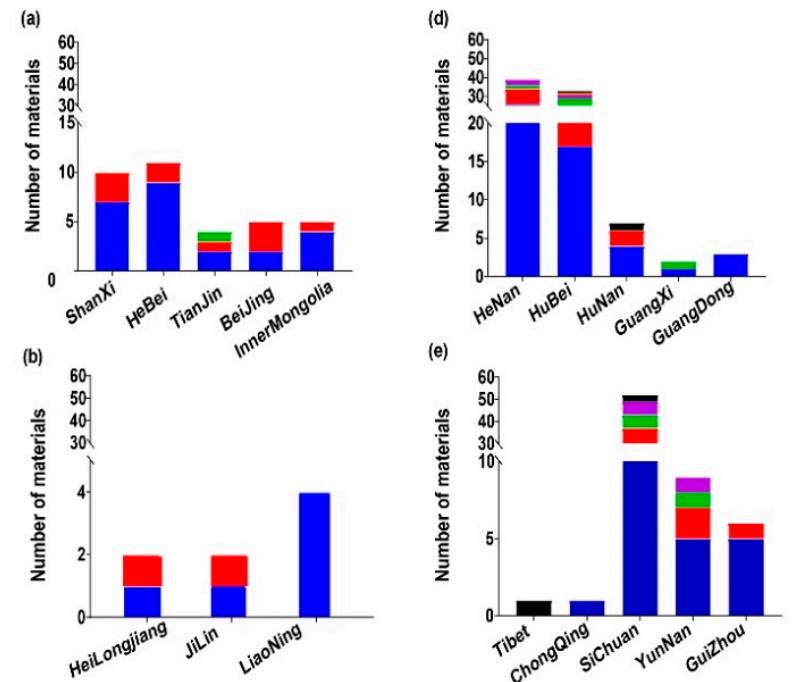

(e)

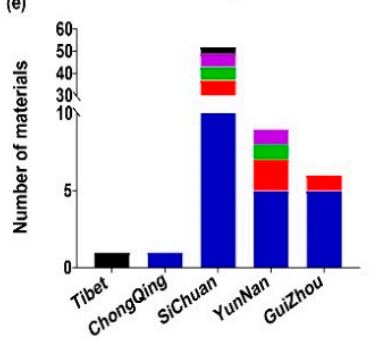

(f)

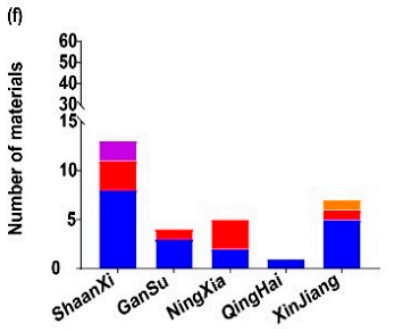

$$
\begin{aligned}
& -\mathrm{I} \\
& -\mathrm{HR} \\
& -\mathrm{R} \\
& -\mathrm{MR} \\
& -\mathrm{S} \\
& -\mathrm{HS}
\end{aligned}
$$

(h)
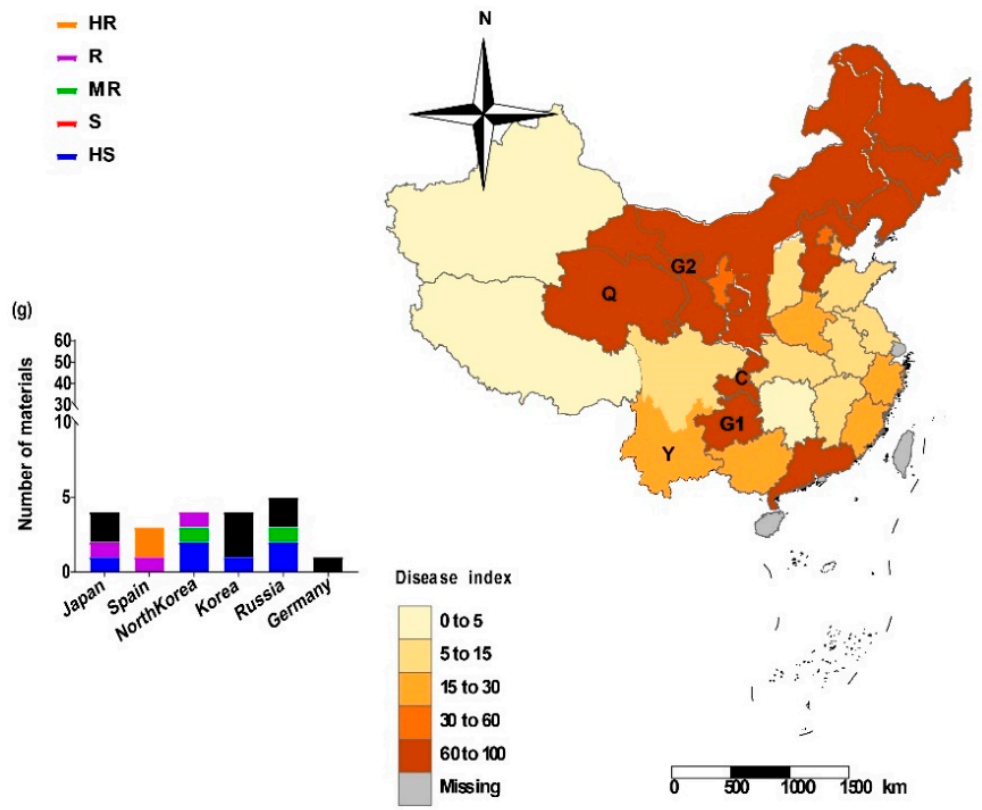

$\begin{array}{llll}0 & 500 & 1000 & 1500\end{array}$

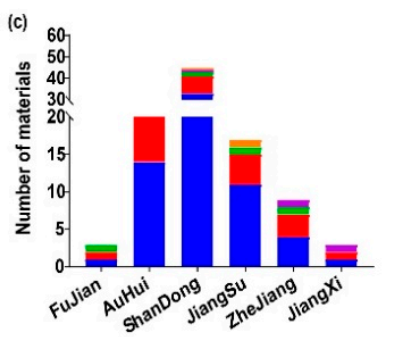

Figure 3. Geographic distribution of radish germplasm resources with different resistance levels to $P$. brassicae. (a) North China; (b) northeast China; (c) east China; (d) south-central China; (e) southwest China; (f) northwest China; (g) radish accessions collected from other countries. In the histograms, I, immune; HR, highly resistant; R, resistant; MR, moderately resistant; S, susceptible; HS, highly susceptible. (h) Map of China showing geographic distribution of the resistance as indicated by the average disease index of the germplasm resources in the corresponding provinces. Q, Qinghai provinces; $Y$, Yunnan provinces; G1, Guizhou; G2, Gansu; C, Chongqing.

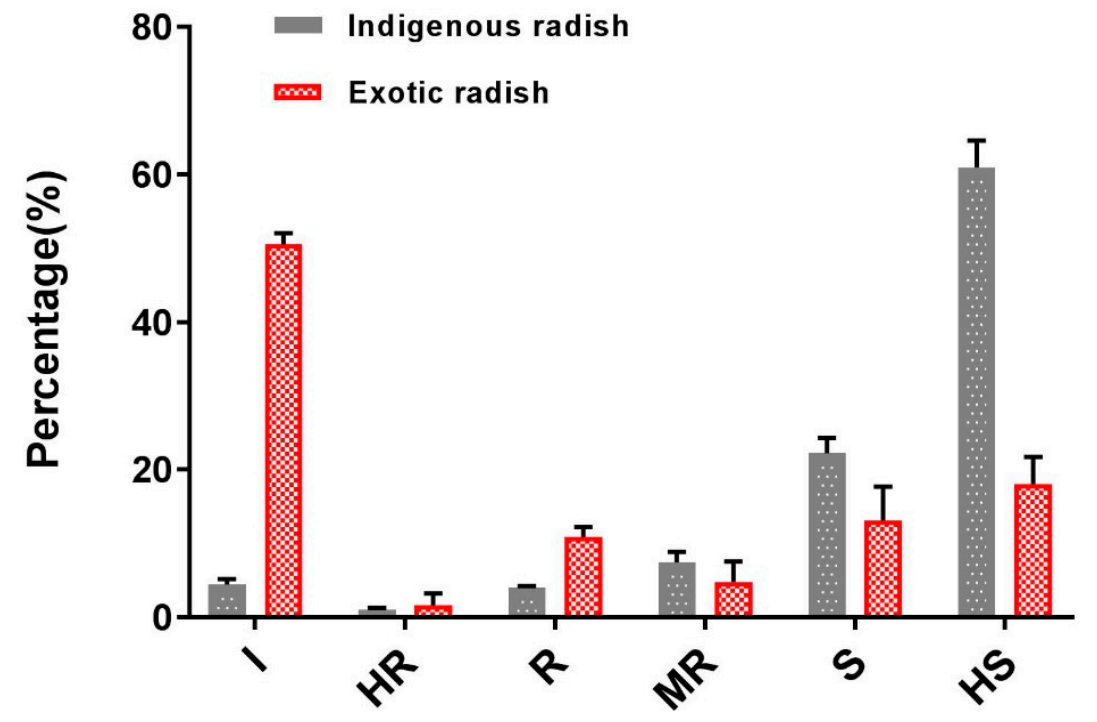

Figure 4. Percentage of indigenous and exotic radish germplasm resources with different resistance levels to $P$. brassicae. I, immune; HR, highly resistant; R, resistant; MR, moderately resistant; $\mathrm{S}$, susceptible; HS, highly susceptible. 


\subsection{Verification of the New Method by Repeated Identification of the Resistance of Immune} Materials and Representative Highly Susceptible Materials

In the second confirming trial-among all immune accessions and ten highly susceptible accessions with DIs varying from 70.85-87.65, identified in the first trial-most still appeared as being immune or highly susceptible in the second trial. There was no significant difference $(p>0.05)$ in disease severity between the two trials (Figure 5$)$ using a paired t-test. In more detail, thirteen materials remained immune, namely, CRR55, CRR221, CRR240, CRR274, CRR281, CRR297, CRR330, CRR340, CRR341, CRR342, CRR346, CRR348, and CRR349 still had no clubroot symptoms, indicating their resistance was stable over repeated trials. However, the resistance of two immune materials (CRR217 and CRR331) changed somewhat. CRR217 became susceptible as the DI increased to 39.51. CRR331 showed slight disease symptoms but remained resistant with a DI of 10.8.

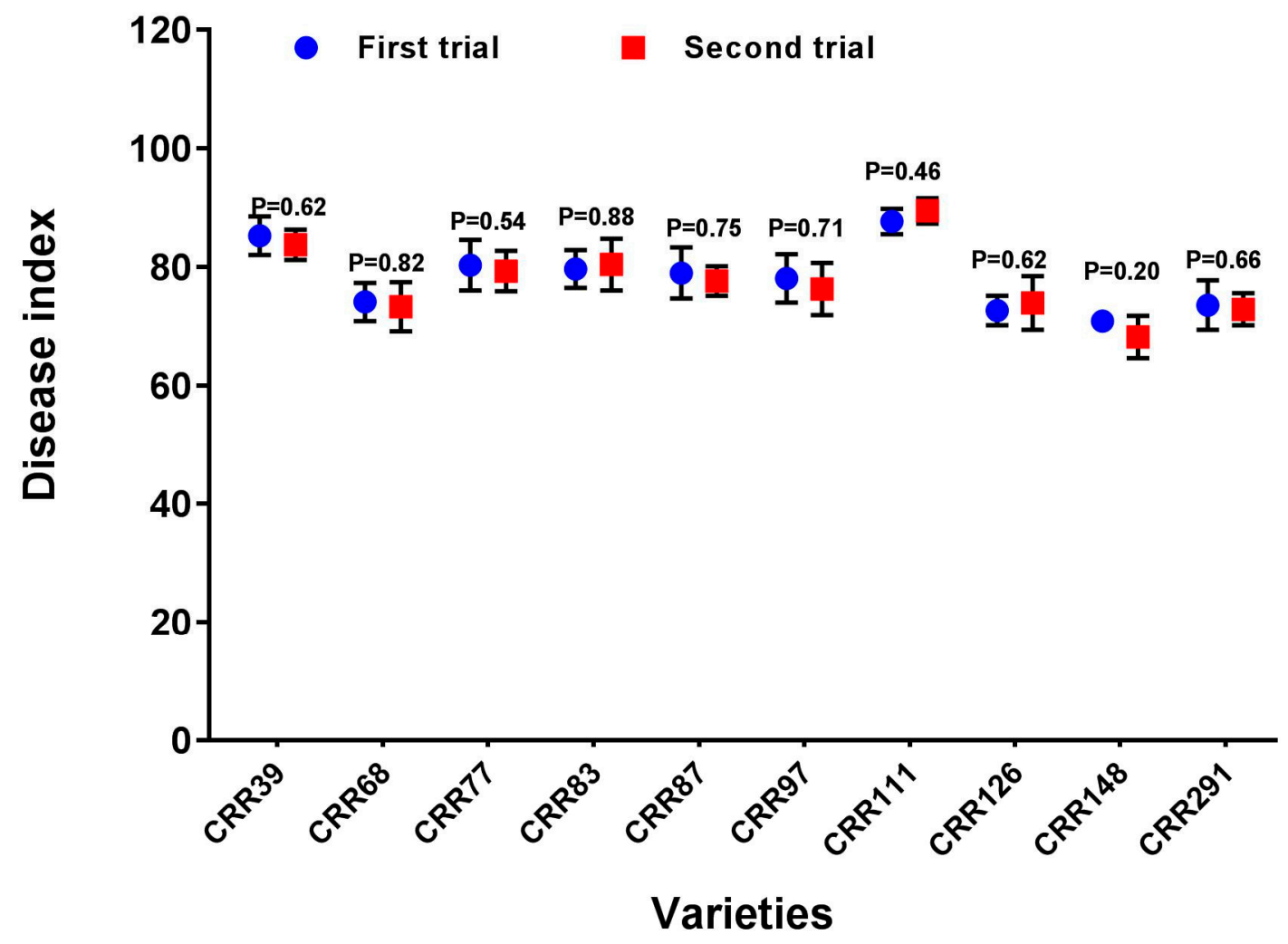

Figure 5. Comparison of the susceptibility of ten highly susceptible accessions to P. brassicae race 4 in two trials. The bar values represent the mean $\pm \mathrm{SE}$ of disease index of each variety in two trials. $p$ values of different varieties were obtained by a paired $\mathrm{t}$-test between the values of two trials at 0.05 level.

\section{Discussion}

Previous studies have most commonly used single-inoculation methods to infect host plants with P. brassicae pathogens, such as the dipping root, clubroot-soil, or soaking inoculation methods $[7,11,57,94,99]$. In the process of inoculation, the clubroot-soil required the inoculum to be fully mixed with the substrate to ensure concentration uniformity of the mixture. Meanwhile, the dipping root method involved dipping the root into inoculum for some time (minutes or hours), and ensuring spore suspension during this time. When a large number of seedlings were identified, these two methods became more complicated and time-consuming. Although the soaking bud method was suitable for large-scale identification, soaking also required preventing the inoculum from settling in a long time. In addition, during the single-inoculation process, no or only a slight infection often occurred in susceptible plants due to environmental change in different stages (such as temperature and humidity) or occasional missing or under-inoculation reasons. In 
our experiment, there were no statistically significant differences among several singleinoculation methods. In other words, the dipping root and clubroot-soil methods used for radish identification did not work as well as in B. rapa and B. oleracea. In contrast, the two-stage combined method was significantly more reliable than single-inoculation. This is probably because radish have a developed taproot with a few lateral roots and fibrous roots, which could result in radish seedlings being easily infected or take a longer time to exhibit symptoms. Among all methods, the two-stage combined inoculation method was the most reliable for the resistance identification of radish germplasm. This could be the reason why this approach prevents both the occasional missing and under-dosed inoculation effects, and also the influence of environmental or plant physiological factors at different developmental stages. The advantages of this method were proven by the results from the resistant evaluation of large-scale radish germplasms and repeated identification of representative resistant and susceptible germplasm resources, although there are a few exceptions that the resistance of CRR217 and CRR331 declined to different degrees in the second trial. These changes in resistance were presumed to be due to insufficient generations of purification or occasional disease escape.

Clubroot disease is hard to manage. Chinese cabbage (B. rapa L.) and cabbages (B. oleracea L.) are generally regarded as being highly susceptible to clubroot disease [7]. Researchers have identified resistant materials from different sources, such as turnip, and successfully bred a few resistant varieties by cross breeding, backcross transformation or pyramiding breeding $[51,100]$. It has been proven that utilization of resistant cultivars is the most effective strategy for clubroot disease control. In radish, early studies indicated that the majority of radish cultivars and inbred lines possess high levels of resistance $[80,101]$. However, the current study showed that most local Chinese radish cultivars were susceptible to $P$. brassicae. Indeed, clubroot disease outbreaks in radish production have been increasing in recent years in many regions of China [3,87], which reflects the lack of clubroot-resistant radish varieties in production. To screen and rationally use the clubroot resistant resources in radish is essential. After all, it is difficult to use Brassica resistant materials of clubroot because the genetic relationship between Raphanus and Brassica is distant.

In this study, we evaluated the resistance of large-scale of radish germplasms with the newly established method and screened a number of radish resistant germplasm resources from China, as well as some highly resistant exotic germplasms. These radish resistant materials could provide diverse resistant sources for managing clubroot by the following different approaches. One management strategy is to apply the resistant cultivars directly to the radish growing regions where race 4 is predominant. The other strategy is to indirectly apply resistant cultivars in radish crossbreeding programs for improving the resistance of varieties. It should be noted that these resistant materials to $P$. brassicae race 4 might be susceptible to other races due to their race specificity. Although at present, other races are less widespread and produce less damage compared with race 4 , they might have the potential to become dominant races in the future. In addition, it has also been reported that the single-gene resistance of some clubroot-resistant cultivars has been overcome in $B$. rapa when genetic resistance was used as a management strategy [102-105]. Therefore, in order to improve the single-gene resistance of radish varieties, polymerizing multiple CR genes, especially with different race specificities, may be more efficient as a clubroot management strategy of genetic resistance utilization. This means that screening and utilization diverse resistant resources, and revealing their resistance genetic background is an urgent requirement for the effective utilization of resistant resources to manage clubroot. However, only a few CR loci have been preliminarily mapped by QTL analysis based on the linkage map in radish so far $[82,106]$. Thus, further studies on the resistant resources discovered in our study are desperately needed.

Through this research, we also discovered new characteristics of clubroot resistance distribution in radish, which will provide clues for us to effectively find and use new resistant resources, and adopt different prevention and control measures for different 
situations. Our results revealed that $71.58 \%$ (204/285) of susceptible materials showed high-susceptibility and displayed distinct swelling or fusiform clubroots, while only $3.72 \%$ $(13 / 349)$ of materials had no symptoms. This indicates that there are more resistant resources in the indigenous materials from the east, southwest, and northwest of China, and exotic germplasms mainly from Korea, Japan and Russia. Specifically, most radish cultivars from northeast and northern China were identified as being highly susceptible, which was also found by Yoshikawa [81]. Some radish cultivars from southwest China have also been seriously infected, especially in Yunnan, Guizhou, and Chongqing provinces (Figure 3h Y, G1, C). Radish cultivars in the above areas have a high level of susceptibility, which is in accordance with clubroot severity in these areas [107]. In the most threatened areas, the soils were heavily polluted and in the short term there is great risk in growing cruciferous crops. In this situation, utilizing resistant cultivars might be the best measure for managing clubroot. In particular, it is noteworthy that native radish cultivars from Qinghai and Gansu provinces (Figure 3h Q, G2) have a high level of susceptibility, while these areas were reported to be clubroot-free in 2013-2014 [106]. One study showed that clubroot risks were low in Qinghai and Gansu since clubroot incidence requires higher resting spore concentrations in the soil [108]. The main clubroot management strategies in these areas should be to avoid disease-free soils from being polluted through various ways or media, considering that all the local cultivars in these areas are characterized by a potential high incidence.

Supplementary Materials: The following are available online at https: / www.mdpi.com/article/ 10.3390 /agronomy11040792/s1, Table S1: Detailed information on the radish accessions that were tested in this study.

Author Contributions: Conceptualization, X.L.; methodology, X.L. and H.Y.; formal analysis, H.Y. and X.L.; investigation, H.Y. and J.S.; resources, Y.Y., X.W. and H.W.; data curation, H.Y. and X.Z.; writing-original draft preparation, H.Y.; writing-review and editing, X.L.; supervision, X.L.; funding acquisition, X.L. All authors have read and agreed to the published version of the manuscript.

Funding: This research was supported by grants from the National Key Research and Development Program of China (2016YFD0100204-02) and the Science and Technology Innovation Program of the Chinese Academy of Agricultural Sciences (CAAS-ASTIP-IVFCAAS, CAAS-XTCX2016016-4-4, CAAS-XTCX2016017).

Data Availability Statement: Data are contained within the article or supplementary material. The data presented in this study are available in A New Identification Method Reveals the Resistance of an Extensive-source Radish Collection to Plasmodiophora brassicae Race 4 or Supplementary Material S1.

Acknowledgments: We want to express our gratitude for the resource aid provided by Quanjie Zhang from Hebei Jierumei Agri-tech Development Co., Ltd.

Conflicts of Interest: The authors declare no conflict of interest.

\section{References}

1. Hirai, M. Genetic analysis of clubroot resistance in Brassica crops. Breed. Sci. 2006, 56, 223-229. [CrossRef]

2. Wang, J.; Huang, Y.L.; Li, X.L.; Li, H.Z. Research progress in clubroot of crucifers. Plant Prot. 2011, 37, $153-158$.

3. Chen, S.L.; Li, Y.L.; Wang, M.X.; Wang, P.S.; Ren, G.C.; Yi, Z.H. Occurrence of clubroot disease of radish in Lushan county. China Plant Prot. 2001, 1, 20.

4. Zhang, R.B. Investigation on Plasmodiophora brassica in Chendu and Hungicides Screening in Field. Master's Thesis, Sichuan Agricultural University, Chengdu, China, 2010.

5. He, J.M.; Hu, J.F.; Dai, Y.J.; Wang, Q.; Wu, L.Y.; Li, S.K.; Li, W.F.; He, Z.R.; Yang, H.L.; Zhong, L. Breeding of club-root resistant ogura CMS backcross line and maintainer line for Brassica Campestris. Hunan Agric. Sci. 2011, 23, 1-5.

6. Zhang, Z.M.; Zhao, Y.T. Identification of new symptom of clubroot disease in white radish. China Plant Prot. 2013, $32,44-45$.

7. Matsumoto, E.; Yasui, C.; Ohi, M.; Tsukada, M. Linkage analysis of RFLP markers for clubroot resistance and pigmentation in Chinese cabbage. Euphytica 1998, 104, 79-86. [CrossRef]

8. Sakamoto, K.; Saito, A.; Hayashida, N.; Taguchi, G.; Matsumoto, E. Mapping of isolate-specific QTL for clubroot resistance in Chinese cabbage (Brassica rapa L. ssp. pekinensis). Theor. Appl. Genet. 2008, 117, 759-767. [CrossRef] 
9. Nikolaev, S.I.; Berney, C.; Fahrni, J.F.; Bolivar, I.; Polet, S.; Mylnikov, A.P.; Aleshin, V.V.; Petrov, N.B.; Pawlowski, J. The twilight of Heliozoa and rise of Rhizaria, an emerging supergroup of amoeboid eukaryotes. Proc. Natl. Acad. Sci. USA 2004, 101, 8066-8071. [CrossRef]

10. Hatakeyama, K.; Suwabe, K.; Tomita, R.N.; Kato, T.; Nunome, T.; Fukuoka, H.; Matsumoto, S. Identification and characterization of Crr1a, a gene for resistance to clubroot disease (Plasmodiophora brassicae Woronin) in Brassica rapa L. PLoS ONE 2013, 8, e54745. [CrossRef] [PubMed]

11. Yu, F.; Zhang, X.; Peng, G.; Falk, K.C.; Strelkov, S.E.; Gossen, B.D. Genotyping-by-sequencing reveals three QTL for clubroot resistance to six pathotypes of Plasmodiophora brassicae in Brassica rapa. Sci. Rep. 2017, 7, 4516. [CrossRef]

12. Nguyen, M.L.; Monakhos, G.F.; Komakhin, R.A.; Monakhos, S.G. The new clubroot resistance locus is located on chromosome A05 in Chinese cabbage (Brassica rapa L.). Russ. J. Genet. 2018, 54, 296-304. [CrossRef]

13. Ingram, D.S.; Tommerup, I.C. The life history of Plasmodiophora brassicae Woron. Proc. R. Soc. B Biol. Sci. 1972, 180, 103-112.

14. McDonald, M.R.; Sharma, K.; Gossen, B.D.; Deora, A.; Feng, J.; Hwang, S.F. The role of primary and secondary infection in host response to Plasmodiophora brassicae. Phytopathology 2014, 104, 1078-1087. [CrossRef] [PubMed]

15. Voorrips, R.E.; Jongerius, M.C.; Kanne, H.J. Quantitative trait loci for clubroot resistance in Brassica oleracea. In Brassicas and Legumes from Genome Structure to Breeding. Biotechnology in Agriculture and Forestry; Nagata, T., Tabata, S., Eds.; Springer: Berlin/Heidelberg, Germany, 2003; Volume 52, pp. 87-104.

16. Pageau, D.; Lajeunesse, J.; Lafond, J. Impact of clubroot (Plasmodiophora brassicae) on the yield and quality of canola. Can. J. Plant Pathol. 2006, 28, 137-143. [CrossRef]

17. Buczacki, S.T.; Ockendon, J.G.; White, J.G. General studies. In Report of the National Vegetable Research Station for 1974; $1974 ;$ p. 113.

18. Wallenhammar, A.C. Prevalence of Plasmodiophora brassicae in spring oil-seed rape growing area in Central Sweden and factors influencing soil infestation levels. Plant Pathol. 1996, 45, 710-719. [CrossRef]

19. Gossen, B.D.; Strelkov, S.E.; Manolii, V.P.; Rennie, D.C.; Cao, T.; Hwang, S.F.; Peng, G.; McDonald, M.R. Spread of Plasmodiophora brassicae on canola in Canada, 2003-2014: Old pathogen, new home. Can. J. Plant Pathol. 2015, 37, 403-413. [CrossRef]

20. Hwang, S.F.; Howard, R.J.; Strelkov, S.E.; Gossen, B.D.; Peng, G. Management of clubroot (Plasmodiophora brassicae) on canola (Brassica napus) in western Canada. Can. J. Plant Pathol. 2014, 36, 49-65. [CrossRef]

21. Botero, A.; García, C.; Gossen, B.D.; Strelkov, S.E.; Todd, C.D.; Bonham-Smith, P.C.; Pérez-López, E. Clubroot disease in Latin America: Distribution and management strategies. Plant Pathol. 2019, 68, 827-833. [CrossRef]

22. Donald, C.; Porter, I. Integrated control of clubroot. J. Plant Growth Regul. 2009, 28, 289. [CrossRef]

23. Hwang, S.F.; Ahmed, H.U.; Strelkov, S.E.; Zhou, Q.; Gossen, B.D.; McDonald, M.R.; Peng, G.; Turnbull, G.D. Suppression of clubroot by dazomet fumigant. Can. J. Plant Sci. 2017, 98, 172-182. [CrossRef]

24. Myers, D.F.; Campbell, R.N.; Greathead, A.S. Clubroot of crucifers in California: Soils respond differently to lime for clubroot control. Phytopathology 1981, 71, 1005-1006.

25. Gossen, B.D.; Kasinathan, H.; Cao, T.; Manolii, V.P.; Strelkov, S.E.; Hwang, S.F.; McDonald, M.R. Interaction of pH and temperature on infection and symptom development of clubroot in canola. Can. J. Plant Pathol. 2013, 35, 294-303. [CrossRef]

26. Peng, G.; Pageau, D.; Strelkov, S.E.; Gossen, B.D.; Hwang, S.F.; Lahlali, R. A > 2-year crop rotation reduces resting spores of Plasmodiophora brassicae in soil and the impact of clubroot on canola. Eur. J. Agron. 2015, 70, 78-84. [CrossRef]

27. Ernst, T.W.; Kher, S.; Stanton, D.; Rennie, D.C.; Hwang, S.F.; Strelkov, S.E. Plasmodiophora brassicae resting spore dynamics in clubroot resistant canola (Brassica napus) cropping systems. Plant Pathol. 2019, 68, 399-408. [CrossRef]

28. Gossen, B.D.; Al-Daoud, F.; Dumonceaux, T.; Dalton, J.A.; Peng, G.; Pageau, D.; McDonald, M.R. Comparison of techniques for estimation of resting spores of Plasmodiophora brassicae in soil. Plant Pathol. 2019, 68, 954-961. [CrossRef]

29. Peng, G.; McGregor, L.; Lahlali, R.; Gossen, B.D.; Hwang, S.F.; Adhikari, K.K.; Strelkov, S.E.; McDonald, M.R. Potential biological control of clubroot on canola and crucifer vegetable crops. Plant Pathol. 2011, 60, 566-574. [CrossRef]

30. Wit, F.; Weg, M. Clubroot-resistance in turnips (Brassica campestris L.). Euphytica 1964, 13, 9-18. [CrossRef]

31. Tjallingii, F. Testing clubroot-resistance of turnips in the Netherlands and the physiologic specialization of Plasmodiophora brassicae. Euphytica 1965, 14, 1-22.

32. Scholze, P.; Hammer, K. Evaluation of resistance to Plasmodiophora brassicae, Alternaria and Phoma in Brassicaceae. ISHS Acta Horticulturae 459. In Proceedings of the International Symposium Brassica, Rennes, France, 23-27 September 1997; pp. 363-372.

33. Ren, L.; Wang, J.; Jia, J.G.; He, Y.Q.; Liu, S.Y.; Fang, X.P. Preliminary study on resistance of cruciferous crops to clubroot disease. In Agricultural Reformation and Rural Progressing: Annual Conference Proceedings of China Agriculture System Engineering Society; Konglai, Z., Zhang, H., Eds.; Aussino Academic Publishing House: Sydney, Australia, 2010.

34. Sharma, P.; Siddiqui, S.A.; Rai, P.K.; Meena, P.D.; Kumar, J.; Chauhan, J.S. Evaluation of Brassica germplasm for field resistance against clubroot (Plasmodiophora brassicae woron). Arch. Phytopathol. Plant Prot. 2012, 45, 356-359. [CrossRef]

35. Tan, C.; Yue, Y.L. Identification of different Chinese cabbage [Brassica campestris L. ssp. pekinensis (Lour) Olsson] varieties resistance to clubroot (Plasmodiophora brassicae). China Veget 2013, 8, 91-94.

36. Huang, X.L.; Ran, Z.H.; Peng, S.S.; Liu, M.J.; Xun, L.F.; Liu, E.M. Identification and evaluation of resistance of Chinese cabbage in Hunan province against clubroot disease. J. Hunan Agric. Univ. Nat. Sci. 2014, 40, $43-47$.

37. Shi, Q.N. Study on Screening of Clubroot Resistance Germplasm Resources and Hybrid Combinations of Chinese Cabbage. Master's Thesis, Northwest A\&F University, Shanxi, China, 2016. 
38. Crisp, P.; Crute, I.R.; Sutherland, R.A.; Angell, S.M.; Bloor, K.; Burgess, H.; Gordon, P.L. The exploitation of genetic resources of Brassica oleracea in breeding for resistance to clubfoot (Plasmodiophora brassicae). Euphytica 1989, 42, 215-226.

39. Manzanares-Dauleux, M.J.; Divaret, I.; Baron, F.; Thomas, G. Evaluation of French Brassica oleracea landraces for resistance to Plasmodiophora brassicae. Euphytica 2000, 113, 211-218. [CrossRef]

40. Carlsson, M.; Bothmer, R.V.; Merker, A. Screening and evaluation of resistance to downy mildew (Peronospora parasitica) and clubroot (Plasmodiophora brassicae) in genetic resources of Brassica oleracea. Hereditas 2004, 141, 293-300. [CrossRef] [PubMed]

41. Si, J.; Li, C.Q.; Song, H.Y.; Ren, X.S.; Song, M.; Wang, X.J. Identification and evaluation of resistance to clubroot in cabbage (Brassica oleracea var. Capitata L.). J. Southwest Univ. Nat. Sci. 2009, 31, 26-30.

42. Hasan, M.J.; Strelkov, S.E.; Howard, R.J.; Rahman, H. Screening of Brassica germplasm for resistance to Plasmodiophora brassicae pathotypes prevalent in Canada for broadening diversity in clubroot resistance. Can. J. Plant Sci. 2012, 92, 501-515. [CrossRef]

43. Ma, D.D.; Pang, S.Q.; Ding, Y.H.; Jian, Y.C.; Geng, L.H. Study on clubroot resistance of different Brassica crops. J. Shihezi Univ. Nat. Sci. 2016, 34, 164-169.

44. Sun, C.; Ma, J.; Lei, L.; Liu, J.; Xie, J.M.; Kang, J.G. Identification of cabbage germplasm resources with resistance to clubroot and sequence analysis of $C R a$ and Crr1a homologous genes from cabbage. J. Plant Genet. Resour. 2016, 17, 1058-1064.

45. Karling, J.S. The Plasmodiophorales: Including a Complete Host Index, Bibliography, and a Description of Diseases Caused by Species of this Order, 2nd ed.; Hafner Publishing Company: New York, NY, USA, 1968.

46. Dixon, G.R.; Doodson, J.K.; Beeney, B.W.; Davies, H.; Jemmett, J.L.; Moxon, R.H. Studies of resistance in swede seed stocks to clubroot (Plasmodiophora brassicae). Plant Var. Seeds 1972, 12, 456-463.

47. Vigier, M.S.; Hum, D.J. Source of resistance to clubroot (Plasmodophom brassicae Wor.) in triazine-resistant spring canola (rapeseed). Can. Plant Dis. Surv. 1989, 69, 113.

48. Gao, Y.; Gao, F.; Li, S.; Peng, S.; Chen, S.; Lin, L. Screening clubroot-resistant germplasm resources from 20 Brassica napus varieties. J. Yunnan Agric. Univ. 2015, 30, 346-356.

49. Liu, Y.; Xu, A.; Liang, F.; Yao, X.; Wang, Y.; Liu, X.; Zhang, Y.; Dalelhan, J.; Zhang, B.; Qin, M.; et al. Screening of clubroot-resistant varieties and transfer of clubroot resistance genes to Brassica napus using distant hybridization. Breed Sci. 2018, 68, 258-267. [CrossRef]

50. Liang, J.H.; Lang, L.N.; Liu, Y.P.; Wang, J.; Zhang, H.; Xu, A.X.; Huang, Z. Resource screening and germplasm creation of Brassica napus resistant to clubroot. Acta Agric. Boreali-Sin. 2019, 34, 219-225.

51. Yoshikawa, H. Breeding for clubroot resistance in Chinese cabbage. In Proceedings of the International Symposium on Chinese Cabbage, Tsukuba, Japan, 31 March-5 April 1980; pp. 405-413.

52. Suwabe, K.; Tsukazaki, H.; Iketani, H.; Hatakeyama, K.; Fujimura, M.; Nunome, T.; Fukuoka, H.; Matsumoto, S.; Hirai, M. Identification of two loci for resistance to clubroot (Plasmodiophora brassicae Woronin) in Brassica rapa L. Theor. Appl. Genet. 2003, 107, 997-1002. [CrossRef] [PubMed]

53. Suwabe, K.; Tsukazaki, H.; Iketani, H.; Hatakeyama, K.; Kondo, M.; Fujimura, M.; Nunome, T.; Fukuoka, H.; Hirai, M.; Matsumoto, S. Simple sequence repeat-based comparative genomics between Brassica rapa and Arabidopsis thaliana: The genetic origin of clubroot resistance. Genetics 2006, 173, 309-319. [CrossRef]

54. Hirai, M.; Harada, T.; Kubo, N.; Tsukada, M.; Suwabe, K.; Matsumoto, S. A novel locus for clubroot resistance in Brassica rapa and its linkage markers. Theor. Appl. Genet. 2004, 108, 639-643. [CrossRef] [PubMed]

55. Piao, Z.Y.; Deng, Y.Q.; Choi, S.R.; Park, Y.J.; Lim, Y.P. SCAR and CAPS mapping of CRb, a gene conferring resistance to Plasmodiophora brassicae in Chinese cabbage (Brassica rapa ssp. pekinensis). Theor. Appl. Genet. 2004, 108, 1458-1465. [CrossRef]

56. Chen, J.; Jing, J.; Zhan, Z.; Zhang, T.; Zhang, C.; Piao, Z. Identification of novel QTLs for isolate-specific partial resistance to Plasmodiophora brassicae in Brassica rapa. PLoS ONE 2013, 8, e85307. [CrossRef]

57. Chu, M.; Song, T.; Falk, K.C.; Zhang, X.; Liu, X.; Chang, A.; Lahlali, R.; McGregor, L.; Gossen, B.D.; Yu, F.; et al. Fine mapping of Rcr1 and analyses of its effect on transcriptome patterns during infection by Plasmodiophora brassicae. BMC Genom. 2014, 15, 1166. [CrossRef]

58. Pang, W.; Liang, S.; Li, X.; Li, P.; Yu, S.; Lim, Y.P.; Piao, Z. Genetic detection of clubroot resistance loci in a new population of Brassica rapa. Hortic. Environ. Biotechnol. 2014, 55, 540-547. [CrossRef]

59. Huang, Z.; Peng, G.; Liu, X.; Deora, A.; Falk, K.C.; Gossen, B.D.; McDonald, M.R.; Yu, F. Fine mapping of a clubroot resistance gene in Chinese cabbage using SNP markers identified from bulked segregant RNA sequencing. Front. Plant Sci. $2017,8,1448$. [CrossRef] [PubMed]

60. Pang, W.; Fu, P.; Li, X.; Zhan, Z.; Yu, S.; Piao, Z. Identification and mapping of the clubroot resistance gene CRd in chinese cabbage (Brassica rapa ssp. pekinensis). Front. Plant Sci. 2018, 9, 653. [CrossRef]

61. Laila, R.; Park, J.I.; Robin, A.H.; Natarajan, S.; Vijayakumar, H.; Shirasawa, K.; Isobe, S.; Kim, H.T.; Nou, I.S. Mapping of a novel clubroot resistance QTL using ddRAD-seq in Chinese cabbage (Brassica rapa L.). BMC Plant Biol. 2019, 19, 13. [CrossRef]

62. Zhu, H.; Zhai, W.; Li, X.; Zhu, Y. Two QTLs controlling clubroot resistance identified from bulked segregant sequencing in pakchoi (Brassica campestris ssp. Chinensis Makino). Sci. Rep. 2019, 9, 9228. [CrossRef] [PubMed]

63. Choi, S.R.; Oh, S.H.; Chhapekar, S.S.; Dhandapani, V.; Lee, C.Y.; Rameneni, J.J.; Ma, Y.; Choi, G.J.; Lee, S.S.; Lim, Y.P. Quantitative trait locus mapping of clubroot resistance and Plasmodiophora brassicae pathotype banglim-specific marker development in Brassica rapa. Int. J. Mol. Sci. 2020, 21, 4157. [CrossRef] [PubMed] 
64. Tomita, H.; Shimizu, M.; Doullah, M.A.; Fujimoto, R.; Okazaki, K. Accumulation of quantitative trait loci conferring broadspectrum clubroot resistance in Brassica oleracea. Mol. Breed. 2013, 32, 889-900. [CrossRef]

65. Landry, B.S.; Hubert, N.; Crete, R.; Chang, M.S.; Lincoln, S.E.; Etoh, T. A genetic map for Brassica oleracea based on RFLP markers detected with expressed DNA sequences and mapping of resistance gene to race 2 of Plasmodiophora brassicae. Genome 1992, 35, 409-420. [CrossRef]

66. Figdore, S.S.; Ferreira, M.E.; Slocum, M.K.; Williams, P.H. Association of RFLP markers with trait loci affecting clubroot resistance and morphological characters in Brassica oleracea L. Euphytica 1993, 69, 33-44. [CrossRef]

67. Grandclément, C.; Thomas, G. Detection and analysis of QTL based on RAPD markers for polygenic resistance to Plasmodiophora brassicae Wor. in Brassica oleracea L. Theor. Appl. Genet. 1996, 93, 86-90. [CrossRef] [PubMed]

68. Voorrips, R.E.; Kanne, H.J. Genetic analysis of resistance to clubroot (Plasmodiophora brassicae) in Brassica oleracea. II. Quantitative analysis of root system measurements. Euphytica 1997, 93, 41-48. [CrossRef]

69. Moriguchi, K.; Kimizuka-Takagi, C.; Ishii, K.; Nomura, K. A genetic map based on RAPD, RFLP, isozyme, morphological markers and QTL analysis for clubroot resistance in Brassica oleracea. Breed Sci. 1999, 49, 257-265. [CrossRef]

70. Rocherieux, J.; Glory, P.; Giboulot, A.; Boury, S.; Barbeyron, G.; Thomas, G.; Manzanares-Dauleux, M.J. Isolate-specific and broads pectrum QTL are involved in the control of clubroot in Brassica oleracea. Theor. Appl. Genet. 2004, 108, 1555-1563. [CrossRef] [PubMed]

71. Nagaoka, T.; Doullah, M.A.; Matsumoto, S.; Kawasaki, S.; Ishikawa, T.; Hori, H.; Okazaki, K. Identification of QTLs that control clubroot resistance in Brassica oleracea and comparative analysis of clubroot resistance genes between B. rapa and B. oleracea. Theor. Appl. Genet. 2010, 120, 1335-1346. [CrossRef]

72. Lee, J.; Izzah, N.K.; Choi, B.S.; Joh, H.J.; Lee, S.C.; Perumal, S.; Seo, J.; Ahn, K.; Jo, E.J.; Choi, G.J.; et al. Genotyping-bysequencing map permits identification of clubroot resistance QTLs and revision of the reference genome assembly in cabbage (Brassica oleracea L.). DNA Res. 2016, 23, 29-41. [CrossRef] [PubMed]

73. Peng, L.; Zhou, L.; Li, Q.; Wei, D.; Ren, X.; Song, H.; Mei, J.; Si, J.; Qian, W. Identification of quantitative trait loci for clubroot resistance in Brassica oleracea with the use of Brassica SNP microarray. Front. Plant Sci. 2018, 9, 822. [CrossRef]

74. Dakouri, A.; Zhang, X.; Peng, G.; Falk, K.C.; Gossen, B.D.; Strelkov, S.E.; Yu, F. Analysis of genome-wide variants through bulked segregant RNA sequencing reveals a major gene for resistance to Plasmodiophora brassicae in Braassica oleracea. Sci. Rep. 2018, 8, 17657. [CrossRef]

75. Piao, Z.; Ramchiary, N.; Lim, Y.P. Genetics of clubroot resistance in Brassica species. J. Plant Growth Regul. 2009, $28,252-264$. [CrossRef]

76. Rahman, H.; Shakir, A.; Hasan, M.J. Breeding for clubroot resistant spring canola (Brassica napus L.) for the Canadian prairies: Can the European winter canola cv. Mendel be used as a source of resistance? Can. J. Plant Sci. 2011, 91, 447-458. [CrossRef]

77. Werner, S.; Diederichsen, E.; Frauen, M.; Schondelmaier, J.; Jung, C. Genetic mapping of clubroot resistance genes in oilseed rape. Theor. Appl. Genet. 2008, 116, 363-372. [CrossRef]

78. Li, L.; Luo, Y.; Chen, B.; Xu, K.; Zhang, F.; Li, H.; Huang, Q.; Xiao, X.; Zhang, T.; Hu, J.; et al. A genome-wide association study reveals new loci for resistance to clubroot disease in Brassica napus. Front. Plant Sci. 2016, 7, 1483. [CrossRef]

79. Zhang, H.; Feng, J.; Hwang, S.F.; Strelkov, S.E.; Falak, I.; Huang, X.; Sun, R. Mapping of clubroot (Plasmodiophora brassicae) resistance in Brassica napus canola. Plant Pathol. 2016, 65, 435-440. [CrossRef]

80. Scheijgrond, W.; Vos, H. Investigation on the susceptibility to club root. Euphytica 1954, 3, 125-139. [CrossRef]

81. Yoshikawa, H. Studies on breeding of clubroot resistance in cole crops (in Japanese with English summary). Bull. Natl. Res. Inst. Veg. Ornam. Plants Tea Japan Ser. A 1993, 7, 1-165.

82. Kamei, A.; Tsuro, M.; Kubo, N.; Hayashi, T.; Wang, N.; Fujimura, T.; Hirai, M. QTL mapping of clubroot resistance in radish (Raphanus sativus L.). Theor. Appl. Genet. 2010, 120, 1021-1027. [CrossRef]

83. Johnston, T.D. Club root in brassica a standard inoculation technique and the specification of races. Plant Pathol. 1968, 17, 184-187. [CrossRef]

84. Guo, X.H. Biological Characteristics and Pathogenesis of Plasmodiophora brassicae. Master's Thesis, Southwest Agriculture University, Chongqing, China, 2001.

85. Si, J.; Li, C.Q.; Xiao, C.G.; Ren, X.S.; Wang, X.J. Study on the inoculation methods of Plasmodiophora brassicae. J. Southwest Univ. (Nat. Sci.) 2003, 25, 216-219.

86. Chen, X.; Wang, C.; Zhang, X.X.; Wang, S. The inoculation system of cabbage clubroot and Screening of resistant germplasm resources. Plant Prot. 2015, 41, 121-126.

87. Zhang, S.X.; Yang, X.Y.; Si, C.G.; Zhang, Q.X.; Wang, Y. Comparision of artificial inoculation identification methods for Chinese cabbage clubroot. Shandong Agric. Sci. 2010, 1, 78-79.

88. Zhao, Y.Y.; Jiang, W.S.; Yuan, Y.X.; Zhang, X.W.; Yao, Q.J.; Zhang, Q.; Wang, Z.Y.; Wei, X.C. Comparison of indoor artificial inoculation methods and conditions of clubroot disease and identification of resistance of different cultivars of Chinese cabbage. Acta Hortic. Sin. 2014, 41, 2675.

89. Suo, H.; Chen, L.Z.; Xu, H.; Song, B.; Fan, X.X.; Yuan, X.H.; He, C.Z. Research on inoculation method of of Plasmodiophora brassicae in no-heading Chinese cabbage. Jiangsu Agric. Sci. 2016, 44, 193-195.

90. Zhu, H.F.; Li, X.F.; Zhu, Y.Y.; Guo, X.X.; Liu, J.P.; Gao, Q.Q.; Zhai, W. Characterization of pak-choi (Brassica chinesis) resistance to clubroot (Plasmodiophora brassica). Acta Agric. Shanghai 2016, 32, 109-113. 
91. Zhang, H.; Zhang, B.; Wang, C.N.; Li, M.; Huang, Z.Y.; Liu, J.F. Study on inoculation methods and condition of clubroot in qingmaye chinese cabbage. Acta Agric. Boreali Sin. 2016, 31, 182-185.

92. Zhang, X.L.; Chai, A.L.; Liu, Y.M.; Fang, Z.Y.; Li, B.J.; Li, Z.S. The development of artificial inoculation system for assessment of resistance to clubroot in broccoli seedlings. J. Plant Pro. 2017, 44, 110-114.

93. Huang, R.; Huang, R.R.; Hua, J.L.; Liang, Y.Y.; Shao, J.Y. Study on Inoculation Methods and Condition of Clubroot in Brassica rapa chinensis. Chinese Agri. Sci. Bulletin 2012, 28, 252-255.

94. Williams, P.H. A system for the determination of races of Plasmodiophora brassicae that infect cabbage and rutabaga. Phytopathology 1966, 56, 624-626.

95. Luo, H.C.; Chen, G.K.; Liu, C.P.; Huang, Y.; Xiao, C.G. An improved culture solution technique for Plasmodiophora brassicae infection and the dynamic infection in the root hair. Australas Plant Pathol. 2013, 43, 53-60. [CrossRef]

96. Yuan, Y.X.; Zhao, Y.Y.; Wei, X.C.; Yao, Q.J.; Jiang, W.S.; Wang, Z.Y.; Li, Y.; Xu, Q.; Yang, S.J.; Zhang, X.W. Pathotype identification of Plasmodiophora brassicae Woron. collected from Chinese cabbage in Henan province. J. Henan Agric. Sci. 2017, 46, 71-76.

97. Hoagland, D.R.; Arnon, D.I. The water-culture method for growing plants without soil. Circ. Calif. Agric. Exp. Stn. 1950, 347, 357-359.

98. Strelkov, S.E.; Tewari, J.P.; Smith-Degenhardt, E. Characterization of Plasmodiophora brassicae populations from Alberta, Canada. Can. J. Plant Pathol. 2006, 28, 467-474. [CrossRef]

99. Hatakeyama, K.; Niwa, T.; Kato, T.; Ohara, T.; Kakizaki, T.; Matsumoto, S. The tandem repeated organization of NB-LRR genes in the clubroot-resistant $C R b$ locus in Brassica rapa L. Mol. Genet. Genom. 2017, 292, 397-405. [CrossRef]

100. Matsumoto, E.; Ueno, H.; Aruga, D.; Sakamoto, K.; Hayashida, N. Accumulation of three clubroot resistance genes through marker-assisted selection in Chinese Cabbage (Brassica rapa ssp. pekinensis). J. Japan Soc. Hort. Sci. 2012, 81, 184-190. [CrossRef]

101. Crute, I.R.; Gray, A.R.; Crisp, P.; Buczacki, S.T. Variation in Plasmodiophora brassicae and resistance to clubroot disease in brassicas and allied crops-A critical review. Plant Breed. Abstr. 1980, 50, 91-104.

102. Kuginuki, Y.; Yoshikawa, H.; Hirai, M. Variation in virulence of Plasmodiophora brassicae in Japan tested with clubroot-resistant cultivars of Chinese cabbage (Brassica rapa L. ssp. pekinensis). Eur. J. Plant Pathol. 1999, 105, 327-332. [CrossRef]

103. Manzanares-Dauleux, M.J.; Divaret, I.; Baron, F.; Thomas, G. Assessment of biological and molecular variability between and within field isolates of Plasmodiophora brassicae. Plant Pathol. 2001, 50, 165-173. [CrossRef]

104. Tanaka, S.; Ito, S. Pathogenic and genetic diversity in Plasmodiophora brassicae (clubroot) from Japan. J. Genl. Plant Pathol. 2013, 79, 297-306. [CrossRef]

105. Strelkov, S.E.; Hwang, S.F.; Manolii, V.P.; Cao, T.; Feindel, D. Emergence of new virulence phenotypes of Plasmodiophora brassicae on canola (Brassica napus) in Alberta, Canada. Eur. J. Plant Pathol. 2016, 145, 517-529. [CrossRef]

106. Gan, C.; Deng, X.; Cui, L.; Yu, X.; Yuan, W.; Dai, Z.; Yao, M.; Pang, W.; Ma, Y.; Yu, X.; et al. Construction of a high-density genetic linkage map and identification of quantitative trait loci associated with clubroot resistance in radish (Raphanus sativus L.). Mol. Breed. 2019, 39, 116. [CrossRef]

107. Li, B.J. Overview of occurrence of major vegetable diseases in 2013 and occurrence trend in 2014. China Veget. 2014, 2, 5-8.

108. Sun, C. Effects of Soil Factors on Clubroot Disease in Main Rapeseed Production Areas; Oil Crops Research Institute, Chinese Academy of Agricultural Sciences: Wuhan, China, 2014. 